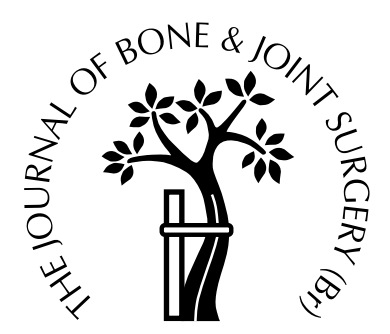

\title{
Fixation of fractures of the midshaft of the clavicle with Kirschner wires
}

\author{
RESULTS IN 108 PATIENTS \\ Chaithavat Ngarmukos, Vinai Parkpian, Adisorn Patradul \\ From Chulalongkorn University, Bangkok, Thailand
}

$\mathbf{W}$ e treated 110 fractures of the middle third of the clavicle in 108 patients aged between 14 and 66 years, by fixation with $2 \mathrm{~mm}$ Kirschner wires.

The wire was introduced, using an air drill and a telescoping guide, from the medial into the lateral fragment. The medial end of the wire which perforated the anterior cortex of the medial fragment was bent backwards to prevent migration into the lung or mediastinum.

In cases of nonunion and acute fracture in which a bone gap was present, bone graft was laid around the fracture site after internal fixation. All the fractures united. No wires broke but in three patients one migrated before union was achieved. Twenty-one patients failed to return for removal of the wire; nine of them had radiological evidence of union before they were lost to follow-up.

J Bone Joint Surg [Br] 1998;80-B:106-8.

Received 16 April 1997; Accepted after revision 12 August 1997

Fractures of the clavicle are usually managed conservatively, ${ }^{1}$ but some may require internal fixation. ${ }^{2-4}$ Pins and wires are commonly used but may migrate even when threaded, and cause damage to vital structures. ${ }^{5-8} \mathrm{We}$ describe a method of fixation of fractures of the middle third of the clavicle using a pair of $2 \mathrm{~mm}$ Kirschner (K) wires, which allows them to migrate outwards only and provides some resistance to rotation.

C. Ngarmukos, MD, Associate Professor

V. Parkpian, MD, Associate Professor

A. Patradul, MD, Associate Professor

Department of Orthopaedic Surgery, Faculty of Medicine, Chulalongkorn

University, Bangkok 10330, Thailand.

Correspondence should be sent to Dr C. Ngarmukos.

(C)1998 British Editorial Society of Bone and Joint Surgery

0301-620X/98/17880\$2.00

106
Patients and Methods

Between September 1974 and December 1996, 2748 patients with fractures of the clavicle were treated at the Chulalongkorn hospital; 2423 were over the age of 14 years. Operation was undertaken using $\mathrm{K}$ wires on 110 fractures in 108 patients. There were 82 males and 26 females with a mean age of 34 years (14 to 66). All the fractures had been caused by road-traffic accidents; 38 patients had associated injuries. There were 99 acute fractures of which seven were open. Eleven fractures had established nonunion.

Operation was undertaken within one week of the injury in 86 patients and within three weeks in 13. We were unable to use the technique in two patients because the fracture was too close to the sternoclavicular joint.

Operative technique (Fig. 1). The patient is placed supine with a folded towel under the affected shoulder. An incision 3 to $5 \mathrm{~cm}$ long is made over the fracture. A minimal amount of soft tissue and periosteum is then released. The medial fragment is grasped with small bone-holding forceps and lifted out of the wound. Using an air drill with a telescoping guide, a $2.0 \mathrm{~mm} \mathrm{~K}$ wire with a diamond tip at each end is driven into the medullary canal of this fragment until the tip perforates the anterior cortex and can be felt beneath the skin. During insertion, the air drill is used at its highest speed, but it should not be pushed hard since the wire will find its own way out of the medullary canal because of the anterior curvature of the medial fragment.

A second wire is then inserted, taking care to retract the first wire caudally so that the second emerges medial and anterior to it. A small incision is made over the emerging wires which are then pushed out far enough to allow the ends to be grasped by a Jacob chuck and pulled medially until clear of the fracture, which is then reduced. The wires are next driven across the fracture site into the medullary canal of the lateral fragment until they just pierce the posterior cortex. The medial ends of the wires are then bent as close to the bone as possible, the excess cut off, and the bent ends impacted so that they hook around the bone, one lying anterior and the other posterior. Any butterfly fragment will usually fall back 


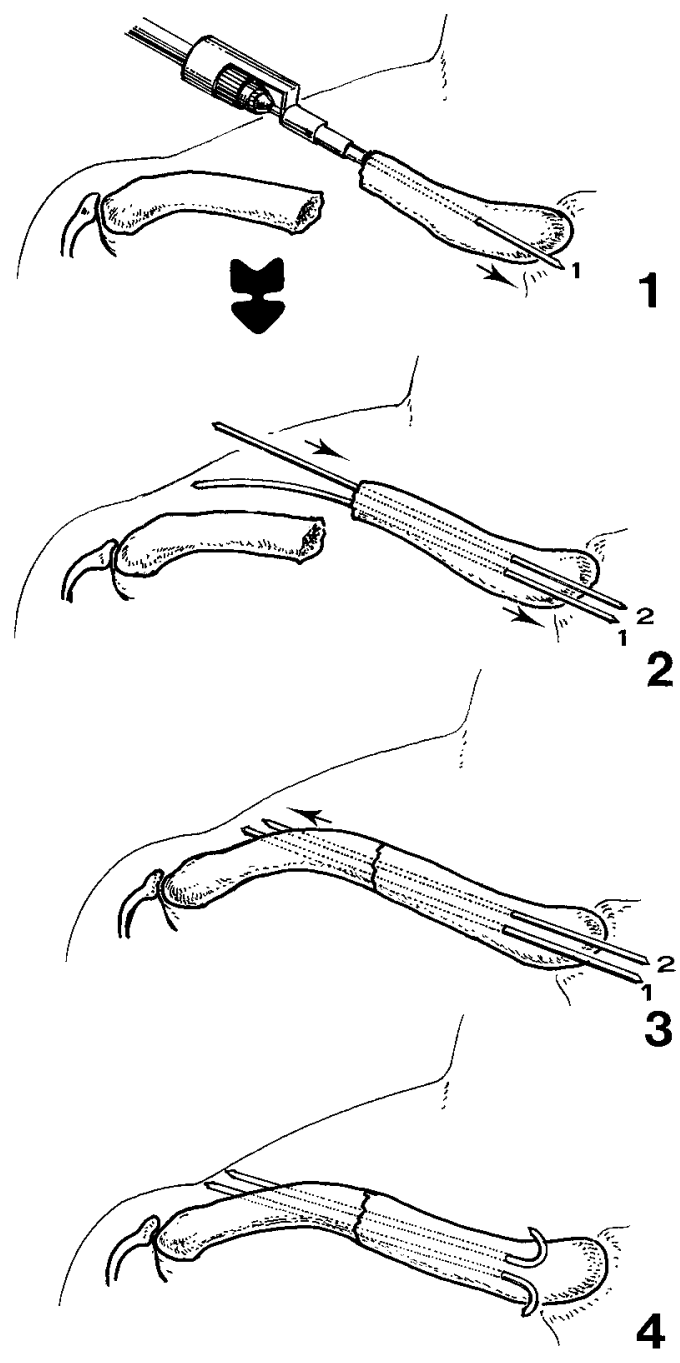

Fig. 1

Diagrams showing the steps in the introduction of the $\mathrm{K}$ wires.

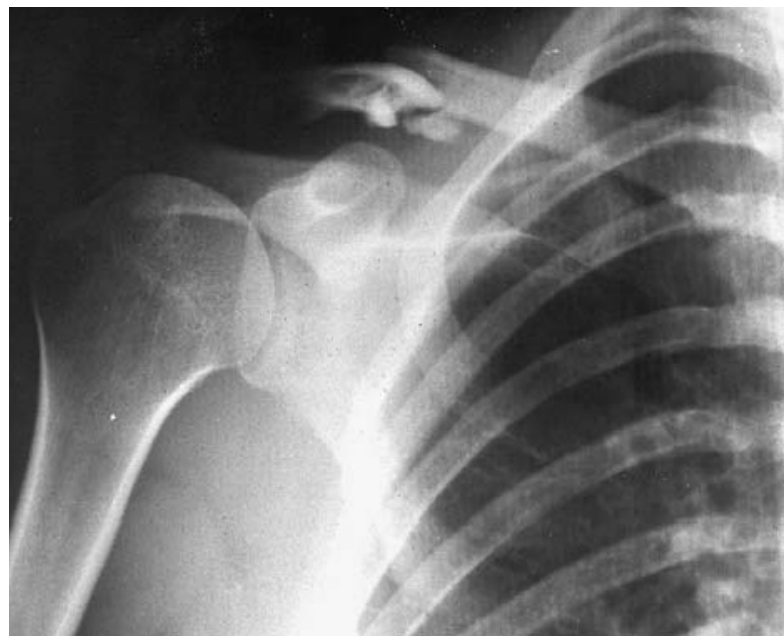

Fig. 2a into position, but should not be freed from soft tissues.

In the cases of nonunion and in the seven acute fractures in which there was a bone gap after fixation, cancellous bone chips from the iliac crest were laid across the fracture site.

The wounds are closed primarily after meticulous haemostasis. A moist saline dressing on top of a single layer of tulle gauze is placed over the wound and changed daily until the wound becomes completely dry, usually in 72 hours. Cephalothin is given intravenously on the first postoperative day and then orally for another four days. Closed suction drainage is used only with bone grafts and is then retained for 48 hours.

The arm is held in a sling for the first three days after surgery and then light daily activities such as writing or eating are allowed. Patients are discouraged from driving, heavy lifting or raising the arm above their head until radiological bony union is apparent. Radiographs are taken every two weeks until the bone joins, and then at six months and at one year before removal of the $\mathrm{K}$ wire.

\section{Results}

Radiological evidence of union was apparent by eight weeks in all the acute fractures and by 20 weeks in the cases of nonunion (Fig. 2). In six patients, five of whom had open fractures, the wound became inflamed. Antibiotics were given and a few stitches removed to allow drainage of a haematoma, but none required early removal of the $\mathrm{K}$ wires. In three patients one of the two $\mathrm{K}$ wires migrated outwards and had to be removed before the fracture was completely united.

Eight patients had symptoms of frozen shoulder which resolved with conservative treatment; three had no associated fractures of the upper limb, but the other five had fractures of the ipsilateral scapula.

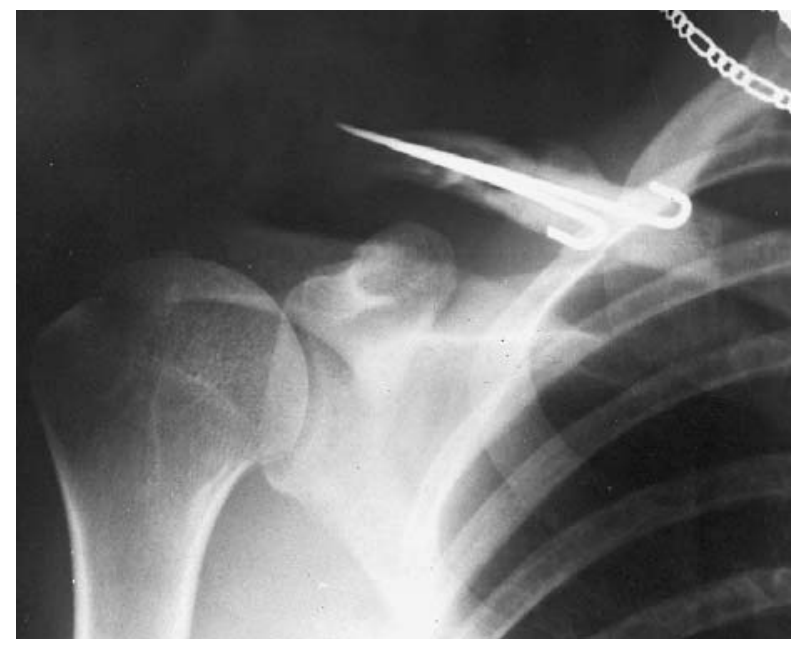

Fig. 2b

Radiographs showing a) comminuted fracture of the middle third of the right clavicle and b) the same fracture after fixation by two $\mathrm{K}$ wires. 
All the wires were removed if possible between six and 12 months after the operation under local anaesthesia, since their bent ends lay just under the skin, but 21 patients failed to return for this procedure. Nine of these already had radiological evidence of union before they were lost to follow-up.

\section{Discussion}

Our method of fixation is simple, but it does require the use of a high-speed drill with a telescoping guide. If the wire becomes loose it will always migrate towards the skin. Skin and soft tissue will resist the bent head more readily than a pointed end. The bent end also hooks snugly around the clavicle. Once the soft-tissue swelling settles the bent wire is quite conspicuous and any migration is easily noticed by the patient. After insertion, the wires bend just a little within the medullary canal when the clavicle springs back into place; a deformed wire will migrate less easily than if it was straight.

The $2 \mathrm{~mm} \mathrm{~K}$ wires are strong enough to allow early, light activities. The parallel arrangement resists rotation, which may otherwise be considerable. ${ }^{9}$ Fixation by a plate has been advocated on the grounds that a single medullary pin cannot control rotation. ${ }^{0-12}$ We support the view that intramedullary fixation will provide an excellent result in terms of healing and function because periosteal stripping is minimal. ${ }^{2,3,4,13}$ None of the fractures in our series failed to unite, probably because of the minimal amount of surgery and the use of bone graft in comminuted injuries. Intramedullary fixation is advantageous in treating nonunion because bone graft can be laid evenly around the fracture site instead of on only one aspect after using a plate and screws. In such cases, excessive callus may cause compression of neurovascular structures at the thoracic outlet. ${ }^{12}$ The scar after intramedullary pin fixation is also smaller and more cosmetically acceptable than after plate fixation. ${ }^{13}$

External fixation ${ }^{14}$ avoids the problem of pin migration but it is cumbersome and more expensive. In a tropical climate the pin-track infection is common and many patients resent the devices.

The amount of pain and disability during the first three weeks of conservative treatment has been underrated ${ }^{2}$ and the common view that nonunion does not occur is wrong. ${ }^{4,15}$ Pressure from a displaced fragment on the retroclavicular part of the brachial plexus may cause symptoms after conservative treatment. ${ }^{16}$

We found our technique very useful for the management of displaced fractures of the middle third of the clavicle, especially in the presence of multiple rib fractures when fixation of the clavicle may help to stabilise the hemithorax

No benefits in any form have been received or will be received from a commercial party related directly or indirectly to the subject of this article.

\section{References}

1. Muller ME, Allgower M, Schneider R, Willenegger H. Manual of internal fixation: technique recommended by the AO group. 2 nd ed. Heidelberg, New York: Springer-Verlag, 1979:166.

2. Rowe CR. An atlas of anatomy and treatment of mid-clavicular fractures. Clin Orthop 1968;58:29-42.

3. Neviaser RJ, Neviaser JS, Neviaser TJ. A simple technique for internal fixation of the clavicle: a long term evaluation. Clin Orthop 1975;109:103-7.

4. Zenni EJ Jr, Krieg JK, Rosen MJ. Open reduction and internal fixation of the clavicular fractures. J Bone Joint Surg [Am] 1981; 63-A:147-51.

5. Kremmens V, Glanser F. Unusual sequela following pinning of medial clavicular fracture. Am J Roentgenol 1966;76:1006-69.

6. Rey-Baltar E, Errazu D. Unusual outcome of Steinmann wire: case of fractured clavicle. Arch Surg 1964;89:1024-5.

7. Norell H, Llewellyn RC. Migration of threaded Steinmann pin from an acromioclavicular joint into the spinal canal: a case report. $J$ Bone Joint Surg [Am] 1965;47-A:1024-6.

8. Lyons FA, Rockwood CA Jr. Migration of pins used in operations on the shoulder. J Bone Joint Surg [Am] 1990;72-A:1262-7.

9. Moseley HF. The clavicle: its anatomy and function. Clin Orthop 1968;58:17-27.

10. Ali-Khan MA, Lucas HK. Plating of fractures of the middle third of the clavicle. Injury 1978;9:263-7.

11. Manske DJ, Szabo RM. The operative treatment of mid-shaft clavicular nonunions. J Bone Joint Surg [Am] 1985;67-A:1367-71.

12. Jupiter JB, Leffert RD. Nonunion of the clavicle: associated complications and surgical management. $J$ Bone Joint Surg [Am] 1987;69-A:753-60.

13. Boehme D, Curtis JR, Deltaan JT, et al. Nonunion of fractures of the midshaft of the clavicle: treatment with a modified Hagie intramedullary pin and autogenous bone grafting. J Bone Joint Surg [Am] 1991;73-A:1219-26.

14. Schuind F, Pay-Pay E, Andrianne Y, et al. External fixation of the clavicle for fracture or nonunion in adults. J Bone Joint Surg [Am] 1988;70-A:692-5.

15. Hill JM, McGuire MH, Crosby LA. Closed treatment of displaced middle-third fractures of the clavicle gives poor results. J Bone Joint Surg [Br] 1997;79-B:537-9.

16. Barbier O, Malghem J, Delaere O, Vande Berg B, Rombouts JJ. Injury to the brachial plexus by a fragment of bone after fracture of the clavicle. J Bone Joint Surg [Br] 1997;79-B:534-6. 